\title{
Changes in Media and Intima of Pulmonary Vessels in Schistosomal Cor Pulmonale (Io Cases)
}

\author{
ELY CHAVES
}

\author{
From the Department of Pathology, Paraiba University School of Medicine, Paraiba, Brazil
}

The pathology of the pulmonary vascular lesions in schistosomal cor pulmonale has been the subject of many earlier publications. Schistosome ova may reach the lungs as emboli and become impacted in the small pulmonary arteries and arterioles, producing a specific acute necrotizing vasculitis which gives rise to an increased pulmonary vascular resistance. This produces pulmonary hypertension of the vascular obstruction type (Bedford, Aidaros, and Girgis, 1946; Machado da Silva and Chaves, 1961; Cavalcanti et al., 1962). The present paper reports observations on structural changes in the media and intima of pulmonary arteries and arterioles in 10 patients who developed the chronic form of schistosomal cor pulmonale. Heath et al. (1958) have documented the relation between altered hæmodynamics in the pulmonary circulation and pathological changes in the pulmonary vessels, and similar changes have been found in the lungs reported here.

\section{Material AND Methods}

Lungs from the necropsies in 10 cases of schistosomal cor pulmonale have been studied in order to investigate microscopically the pulmonary vascular changes. The lungs were fixed in 10 per cent formalin, and tissue blocks were cut and embedded in paraffin wax. Serial sections of the blocks were stained by the following methods: Weigert's fibrin, hæmatoxylin and eosin, Mallory's phosphotungstic acid hæmatoxylin, Masson's trichrome, Gomori's reticulin, Weigert's elastic tissue, and van Gieson's stains.

\section{RESULTS}

The most striking features appeared in the media and intima of pulmonary arteries and arterioles, and the lesions were classified in two types according to their severity.

Received June 29, 1965.
Type I (5 cases). The lumina of these vessels were very narrowed by extensive intimal thickening formed by cellular concentric or eccentric masses of fibrous tissue (Fig. 1). The endothelial cells were sometimes prominent and plump. There was little-to-moderate medial hypertrophy (Fig. 2) never reaching more than 15 per cent of the external diameter. Muscular hypertrophy was sometimes accompanied by moderate intimal fibrocellular proliferation and less frequently by elastosis. There were no intimal abnormalities elsewhere in the pulmonary arterial tree.

Type II (5 cases). In these cases the vessels showed a more widespread occlusion by intimal fibrous thickening (Fig. 3). Recanalization of the intimal fibrous occlusion was a constant feature in 2 cases. The internal elastic lamina was often thickened and reduplicated and in places produced a noticeable narrowing of the lumen. The medial hypertrophy was more pronounced than in Type I and often reached 25 per cent of the external diameter of the vessel (Fig. 4). Many vessels contained thrombi in various stages of organization: some showed recanalization and many of these contained recent thrombus. Many arteries showed a healing phase of arteritis: granulation tissue replaced part of the intima and media and extended through the adventitia.

\section{Discussion}

The morphology of hypertensive pulmonary vascular lesions in chronic schistosomal cor pulmonale has been compared with that occurring in patent ductus arteriosus (Brewer, 1955), and in certain cases of primary pulmonary hypertension and in pulmonary hypertension complicating septal cardiac defects (Chaves, 1960). The massive and repeated embolization of schistosome ova in the 599 


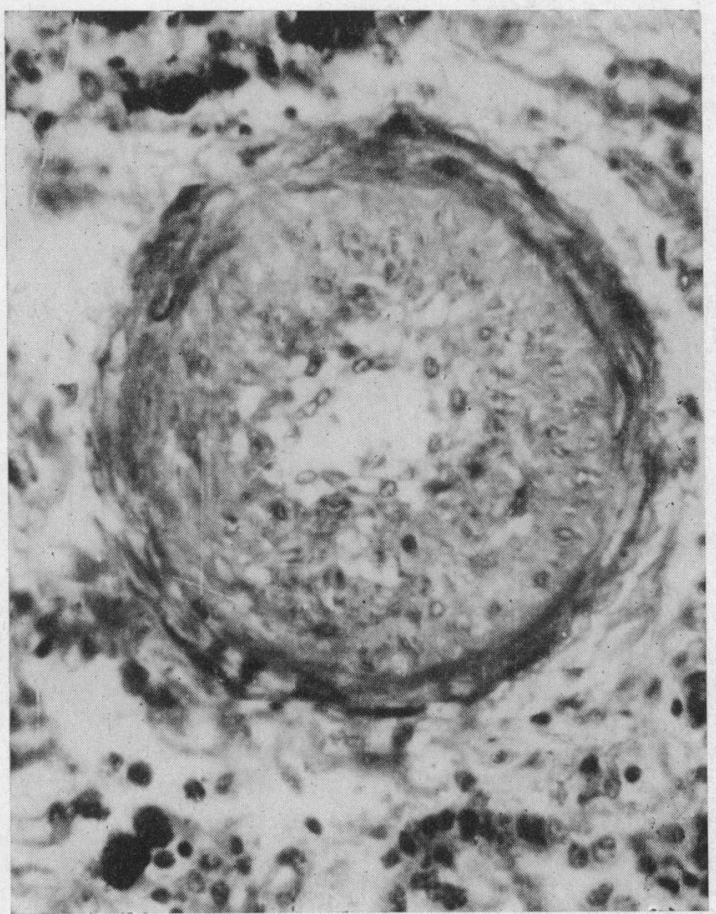

FIG. 1.-Muscular pulmonary artery with lumen almost obliterated by cellular intimal proliferation. (Hæmatoxylin and eosin. $\times 400$.)

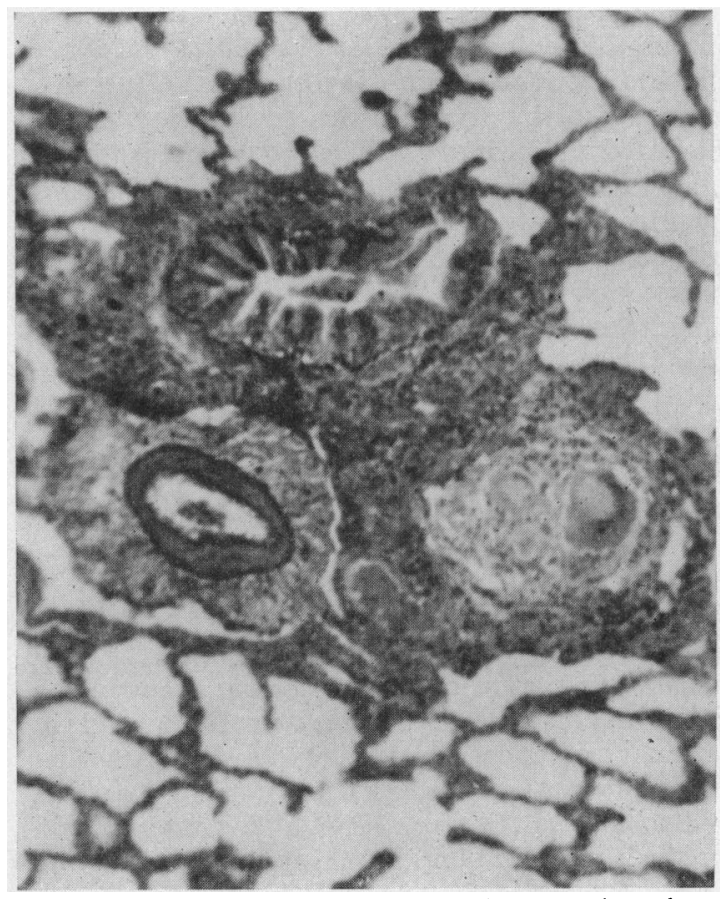

Fig. 2.-Muscular pulmonary artery adjacent to bronchus, showing medial hypertrophy. (Gomori's reticulin. $\times 100$.)

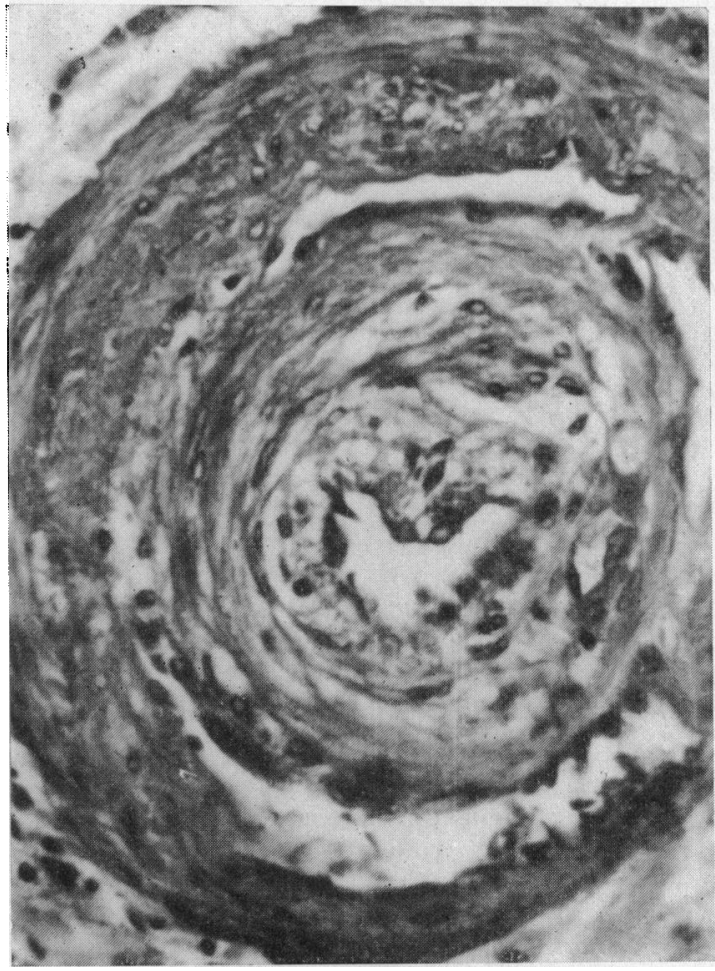

FIG. 3.-Muscular pulmonary artery with recanalized lumen. (Masson's trichrome. $\times 400$.)

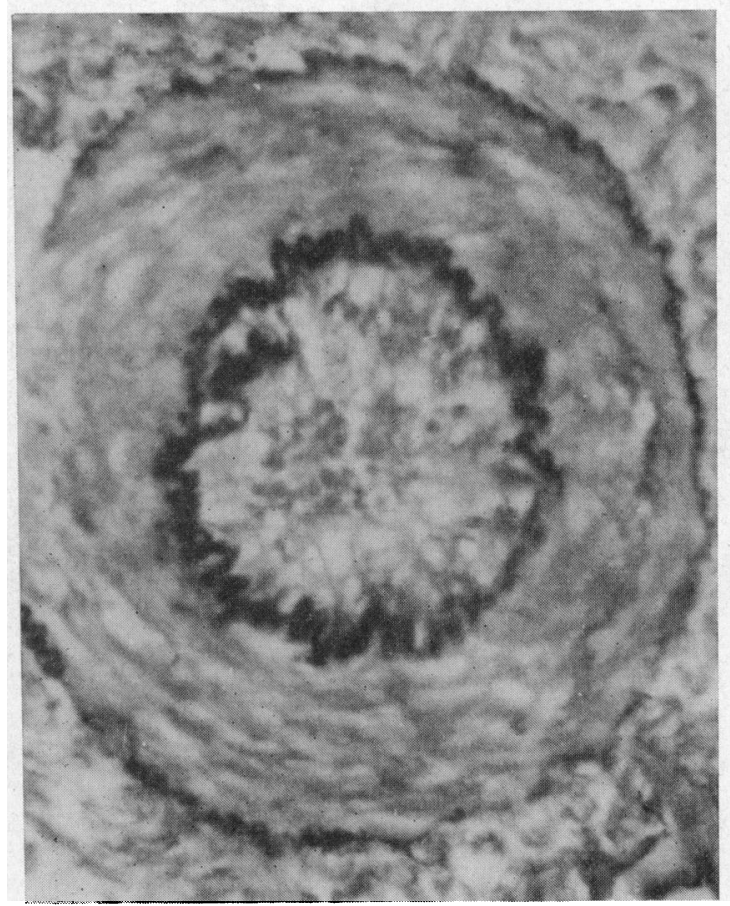

Fig. 4.-Muscular pulmonary artery: the arterial media is very hypertrophied. (Gomori's reticulin. $\times 400$.) 
arteritis and arteriolitis. This raises pulmonary vascular resistance, with eventual pulmonary hypertension and right-sided cardiac hypertrophy (Kenawy, 1950; Marchand et al., 1957). The vascular changes associated with pulmonary hypertension are most clearly observed in the media and intimal layer of the arterioles and small pulmonary arteries.

Heath and Edwards (1958) described lesions in pulmonary arteries and arterioles in cases of congenital cardiac septal defect with chronic elevation of the pulmonary arterial blood pressure; they classified six different and transitional types of vascular change, graded according to the severity of the lesion. The vascular lesions found in pulmonary schistosomiasis have been assigned to grades in the Heath and Edwards (1958) classification. Our Type I was found to correspond to Heath and Edwards' Grades I and II-i.e. there was slight or moderate intimal proliferation, often with medial hypertrophy (up to 15 per cent of the external diameter) of the small arteries and arterioles. Type II was found to correspond to Heath and Edwards' Grades III, IV, and V, i.e. severe intimal proliferation and marked medial hypertrophy (up to 25 per cent of the external diameter). In Type II thrombotic lesions were also seen, often with recanalization which sometimes had a plexiform appearance (Chaves, 1965).

\section{SUMMARY}

Observations on the intimal and medial changes in muscular pulmonary arteries and arterioles in 10 cases of schistosomal cor pulmonale have been presented. The progressive vascular changes were divided into two types according to the severity of the lesions. In Type I the vascular lesions were characterized by intimal proliferation with little or moderate medial hypertrophy. In Type II the chief alterations were intimal fibrosis, moderate to marked medial hypertrophy, thickening, and reduplication of the internal elastic lamina, and thrombotic lesions, many of which showed recanalization.

\section{REFERENCES}

Bedford, D. E., Aidaros, S. M., and Girgis, B. (1946). Bilharzial heart disease in Egypt: cor pulmonale due to bilharzial pulmonary endarteritis. Brit. Heart $\mathcal{F} ., 8,87$.

Brewer, D. B. (1955). Fibrous occlusion and anastomosis of the pulmonary vessels in a case of pulmonary hypertension associated with patent ductus arteriosus. f. Path. Bact., 70, 299.

Cavalcanti, I. de L., Tompson, G., de Souza, N., and Barbosa, F. S. (1962). Pulmonary hypertension on schistosomiasis. Brit. Heart f., 24, 363.

Chaves, E. (1960). Cor pulmonale cronico esquistossomótico.I. Estudo das les ̃es vasculares associadas à hipertensão pulmonar. Rev. Inst. Med. trop. S. Paulo, $2,78$.

- (1965). O trombo hialino no cor pulmonale crônico esquistossomótico. Rev. Inst. Med. trop. S. Paulo, 7, 11.

Heath, D., and Edwards, J. E. (1958). The pathology of hypertensive pulmonary vascular disease; a description of six grades of structural changes in the pulmonary arteries with special reference to congenital cardiac septal defects. Circulation, 18, 533.

-, Helmholz, H. F., Jr., Burchell, H. B., DuShane, J. W., and Edwards, J. E. (1958). Graded pulmonary vascular changes and hemodynamic findings in cases of atrial and ventricular septal defects and patent ductus arteriosus. Circulation, 18, 1155.

Kenawy, M. R. (1950). The syndrome of cardiopulmonary schistosomiasis (cor pulmonale). Amer. Heart f., 39, 678.

Machado da Silva, R., and Chaves, E. (1961) Cor pulmonale crônico esquistossomótico. III. Estudo clinico-patológico de 6 casos. Hospital (Rio de f.), 60, 455.

Marchand, E. J., Marcial-Rojas R. A., Rodríguez, R., Polanco, G., and Díaz-Rivera, R. S. (1957). The pulmonary obstruction syndrome in Schistosoma mansoni, pulmonary endarteritis. Arch. intern. Med., $100,965$. 